\title{
Research on the Effective Education Mode based on MOOC Platform and Traditional Teaching Auxiliary Pattern
}

\author{
Lili Ban \\ Hebei Academy of Fine Arts, \\ Shijiazhuang City of Hebei Province, 050700
}

\begin{abstract}
In this paper, we conduct research on the effective education mode based on the MOOC platform and traditional teaching auxiliary pattern. MOOC course content covers many disciplines, from natural science to humanities curriculum exists or not is entirely up to the student's popularity. In MOOC system, teachers choose not to the scientific research ability and academic level of success or failure completely depends on the level of teaching. Curriculum design is reasonable, use appropriate technology, and explain easy-to-read widely welcomed by students, teachers and will only be scripted teachers cannot survive. Curriculum development engineers pay more attention to the research of the human brain's attention and learning characteristics, and on the basis of using technology to complete the course. It is this learning theory and the combination of technology, expanded the MOOC vitality and set off another round of study the trend of the change.
\end{abstract}

Keywords- MOOC Platform, Traditional Teaching, Effective Education, Auxiliary Pattern Mode.

\section{Introduction}

With the help of the new media have already the idea of education activities, such as the fine course, remote network education, etc. but limited by the time of the technical level, the education form has not been widely used. As information technology, computer technology, the development of mobile Internet technology progress, web-based learning mode also gradually mature and perfect as a new curriculum mode, modern MOOC compared with the traditional curriculum model has its remarkable characteristics, but both also have some in common. MOOC and applied university course differences mainly displays in the following respects.

- Teaching interaction patterns are different. The MOOC teaching high school students have problems mainly by the network query, online question solution, the teachers and students in the university courses can communicate face to face.

- The course of language and culture differences. MOOC quite a part of the course is not in the local language scholars, this leads to students may encounter in the process of learning the language barrier, such as students to effective learning of English are not familiar with foreign MOOC course that may cause some difficulties.

- Teaching organization form is different. MOOC of teaching organization is loose, mainly by students' self-consciousness. Applied university teaching organization, strict teaching process should be according to the teaching plan and syllabus, generally uses a combination of the classroom teaching and practice teaching [1-3].

- Course structure and number of students is not the same. The applied university students are mainly students, the general major similarity degree is higher, student learns basic difference, while students of MOOC may from around the world as the basic level difference is bigger. 
In the process of the development of the MOOC appeared different modes, from the perspective of learning theory, MOOC can be divided into cMOOC and $\mathrm{xMOOC}$ two modes. cMOOC emphasis is to build up the knowledge and the mode of autonomous learning, this kind of mode, teachers are not dominant course, learners have more autonomy in learning course, learners learn to autonomously in the network resources after course content, course shared resource extraction and learn knowledge, and then discussed through social media communication tools such as communication, knowledge of the systematic construction. To the learners' self-discipline ability and the learning ability have higher requirements. xMOOC focus more on the spread of knowledge and the leading study, close to the traditional teaching mode, but xMOOC stressed and test content such as video teaching, homework, learning content for learners to elaborate design, improve the learning interest, help learners master the knowledge, building knowledge system. The figure one shows the corresponding keywords.

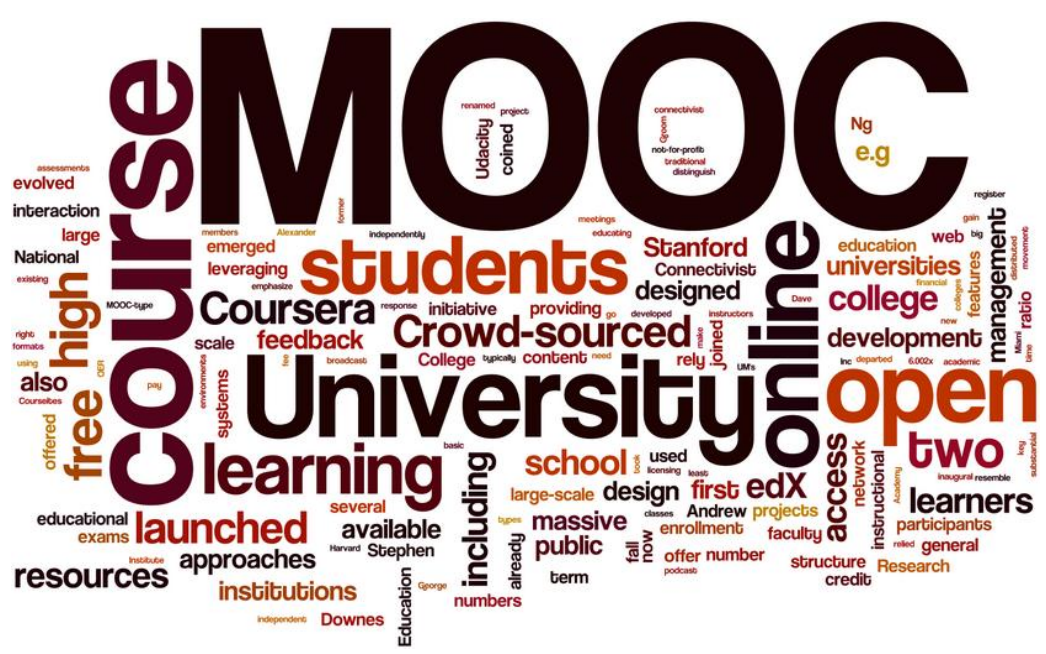

Figure 1. The Keywwords of the MOOC Education Platform

In this paper, we conduct research on the effective education mode based on MOOC platform and traditional teaching auxiliary pattern. In the later sections, we will analyze the features of MOOC, the combination of traditional teaching paradigm and the future development orientation, respectively. More in-depths analysis could be achieved in the following parts.

\section{The Proposed Methodology}

The Basic Features of College Education Mode. In the process of the teaching in colleges and universities, imparting of knowledge is important, but more important is to make students form the correct learning method and the very strong self-learning ability, cultivate the students' scientific spirit and sound personality, which provide good foundation for the development of students' life. Although our country colleges and universities teaching reform have been for many years, from the overall, the effect is not ideal. Therefore, to transform the pattern of traditional education, truly quality education and integration of the university teaching process that is the key to promote the reform of the college teaching. The scientific outlook on development is the methodology of advancing the reform and development of various undertakings, is the work of the party and the state's thought weapon and is entrepreneurship education in colleges and universities must follow the basic principles of scientific development. Therefore, in order to 
fully play the role as the core of entrepreneurship education in the colleges and universities, institutions of higher learning must be guided by the scientific concept of the development principle, develop targeted, scientific and the innovative entrepreneurship education teaching mode, change the outdated education model, the road of sustainable development to explore the creative education atmosphere [4-5].

Correspondingly, the principles of the college education mode could be summarized as following aspects. (1) Because the innovative talent training oriented teaching for modern teachers' professional knowledge and teaching skills has a very high demand, therefore, teachers should first of all and the teaching mode has a deep understanding and awareness, to grasp the true value of the teaching mode and essence connotation. International teaching mode of series of studies has shown that although the different teaching mode of teaching theory and teaching ideas, but in fact, these are not mutually exclusive to each other between teaching mode, but are used in general specific teaching situation. (2) Considering the student teachers face great differences, therefore, the choice of teacher's teaching activities and arrange to pay attention to students' differences. Pay attention to students' differences in education is essentially people-oriented education, which is basis of the implementation of innovative education is extremely important. (3) Because university level and type of diversification, teaching task and orientation of colleges and universities there are obvious differences. This kind of variety and differentiation will produce very big effect to teachers' teaching activities, therefore, the design of the teachers' teaching activities, we must give full consideration to the characteristics of different types of colleges and universities that make the design requirement have the situation adaptability. Students' innovative ability training is the era of all the colleges and universities should shoulder the important mission, but different types of colleges and universities can be different on cultivation of measures.

Emphasize teaching take the student as the main body, does not mean that the role of teachers in teaching is reduced, requirement for teachers' higher instead. College teachers should not only master the professional knowledge, be familiar with in the information age growth of new college students, to understand their cognitive abilities, interests, hobbies, multi-media and the network technology, familiar with library resources as much as possible to give effective guidance to the students' creative. Colleges and universities must strengthen the recognition of the second classroom education actively improve the practice of the second classroom environment to deepen the course education and the comprehensive reform of extracurricular practice. Through to establish and perfect the related system of the second classroom, further enhance the learning ability of college students, stimulate students' creative thinking, to promote effective development of college students' employment education mode.

The MOOC and Characteristics. MOOC large-scale online open course is the emergence of the open education field in recent years a new type of curriculum pattern, is free for the social public open online courses, it is made up of a number of the sharing and cooperation spirit, willing to enhance the knowledge of individual or the organization issued by, spread on the Internet, open and the large-scale course, has the massive learning resources, large-scale distributed learning partners, a variety of the distributed network learning support services, the characteristics of openness, self-organization and sociality. With the several years' development, it has been developed with large extent, which is as the reflection of the following figure two [6]. 


\section{MOOC 1.0}

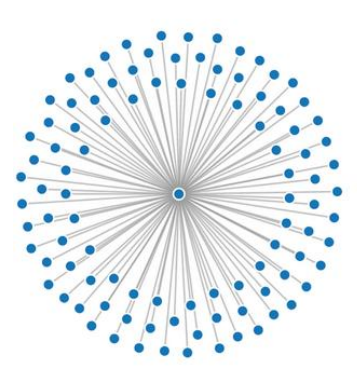

MOOC 2.0

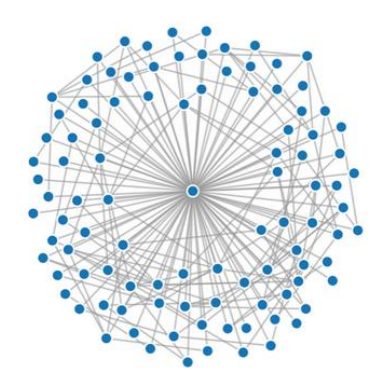

Figure 2. The Development of the MOOC Education Pattern

Therefore, we could summarize the features of MOOC as follows. (1) Openness. Openness is one of the characteristics of Internet born, MOOC openness expanded the openness of the Internet, has the characteristics of multiple levels of open. One is the course free of space and time, MOOC study is not restricted by the time and space, the terminal using mobile learning at any time and any place all can participate in the course, get rid of the traditional physics classroom space and time limit. Second it is open and free global learners, in addition to the learners to apply for course certificate need to pay a fee, the data, resources, open and the free content and services to the global learners, learners can be barrier-free access to the curriculum resources, free access to information and knowledge. (2) Provide diverse learning resources and personal support services. Through the analysis of large data mining, cloud learning environment for universal's autonomous learning, lifelong learning, push personalized education resources, in order to realize the information system and intensive utilization of resources integration, and realize exchange of data integration and sharing, for learners to provide personalized, diversification of learning resources and support services. (3) Property of the participation. MOOC learning environment using the Internet to automatic tracking and recording function, record and save the learners' learning behavior in the course learning activities, the use of learning behavior analysis algorithm for mining the back of a big data information and rules, the formative assessment results timely feedback to the learners and the teaching, guidance for the learners to provide the personalized learning, help teachers to understand the curriculum teaching effect, improve teaching strategies and the methods, scientifically, comprehensively improve the quality of teaching [7].

MOOC course than traditional online courses more deeply which can well realize the students' autonomous learning, but it is only online learning is not entirely bearing teaching the whole idea of information literacy class teaching, also cannot replace between teachers and students and students "face to face" interaction and communication between, cause lack of collective learning atmosphere, students can't master knowledge system. Therefore, the MOOC advocated blended learning under the environment of information literacy education with the "double interaction" online. Because MOOC fragmentation learning mode is more suitable for offline self-study mode, learners can make use of spare time to watch video, according to the need of autonomous for knowledge don't understand, also can use the Internet to check the related information, continue to learn, at the same time MOOC and full participation in the whole process of the teaching course, learners in-class test online, participate in the discussion and the online FAQ as is more advantageous to develop the blended learning in the practical teaching. In the actual use of blended learning mode in the 
pheromone education courses, we may consider such blended learning model based on MOOC.

The Future of the University Informatization. University informatization refers to with the development of modern information technology, colleges and the universities according to their own development needs, the use of advanced information technology to build digital campus, to improve management efficiency, strengthen the teaching quality, enhance service level, promote the scientific research. As the main place of cultivating talents in colleges and universities, how to make full and effective use of the information technology offers huge potential, deepen the reform of the school to realize education development, improve the development of colleges and universities, to realize the transition of the function of the school management, the formation of the efficient and dynamic new management mechanism, improve the education quality of teaching, improve teaching efficiency is important. The following suggestions are our experience with daily applications.

- We must pay attention to training of informatization talents, ensuring stable operation system. In the process of the information construction of colleges and universities, from all of the information literacy of determines the results of the information technology application, to determine the degree of the education teaching informationization. Therefore, do a good job in the popularization of information technology and training to improve the general teachers and students and workers using the level of information technology and awareness has become the current university informatization construction an important basic work.

- To have a scientific overall plan. Specific implementation according to the actual situation of school, when we collect all aspects of the opinions and views, consulting relevant experts in the field of under leadership of the leadership of the school, through the relevant departments of the groove to form a general unified plan [8].

- To go the most suitable for their characteristics of the informatization construction of roads and construction mode. Colleges and universities in process of implementing informatization cannot copy foreign mode and mode of other universities and also can't copy the school the original model. To adapt to the needs of social development, according to the current situation of development of university informatization, creatively put forward some exploration plan to make the information construction of colleges and universities has its own characteristics.

\section{Conclusion}

In this paper, we conduct research on the effective education mode based on MOOC platform and the traditional teaching auxiliary pattern. In recent years, the massive open online courses boom rising, both in school and education industry, individual teacher, are actively concerned, strong investment, actively respond to. MOOC is a new form of network remote education is also a new opportunities and challenges. This article from the perspective of a teacher, some key problems in analysis and the elaboration MOOC construction: the MOOC demand and orientation, main part of the construction of the MOOC with different forms of online courses using effect. We enhance the traditional classroom based education with the MOOC to optimize the performance of the teaching activities. In the later research, we will conduct more in-depth analysis on MOOC and the corresponding variant to propose better modified approaches for future education scenarios. 


\section{References}

[1] Breslow, Lori, et al. "Studying learning in the worldwide classroom: Research into edX's first MOOC." Research \& Practice in Assessment 8.1 (2013): 13-25.

[2] Pham, Phuong, and Jingtao Wang. "AttentiveLearner: Improving Mobile MOOC Learning via Implicit Heart Rate Tracking." (2015).

[3] Konstan, Joseph A., et al. "Teaching recommender systems at large scale: Evaluation and lessons learned from a hybrid MOOC." ACM Transactions on Computer-Human Interaction (TOCHI) 22.2 (2015): 10.

[4] De Waard, Inge, et al. "Merging MOOC and mLearning for increased learner interactions." International Journal of Mobile and Blended Learning (IJMBL) 4.4 (2012): 34-46.
[5] Sadigh, Dorsa, Sanjit A. Seshia, and Mona Gupta. "Automating exercise generation: A step towards meeting the MOOC challenge for embedded systems." Proceedings of the Workshop on Embedded and Cyber-Physical Systems Education. ACM, 2012.

[6] Aguaded-Gomez, J. Ignacio. "The MOOC Revolution: A new form of education from the technological paradigm." Comunicar 41 (2013): 7-8.

[7] Romero, Margarida. "Game based learning MOOC. Promoting entrepreneurship education." Elearning Papers, Special Edition MOOCs and Beyond 33 (2013): 1-5.

[8] Sinha, Tanmay, and Justine Cassell. "Connecting the Dots: Predicting Student Grade Sequences from Bursty MOOC Interactions over Time." Proceedings of the Second (2015) ACM Conference on Learning@ Scale. ACM, 2015. 